\title{
Thermal Hyperalgesia in Association with the Development of Morphine Tolerance in Rats: Roles of Excitatory Amino Acid Receptors and Protein Kinase C
}

\author{
Jianren Mao, Donald D. Price, and David J. Mayer \\ Department of Anesthesiology, Medical College of Virginia, Virginia Commonwealth University, Richmond, Virginia 23298
}

In a rat model of morphine tolerance, we examined the hypotheses that thermal hyperalgesia to radiant heat develops in association with the development of morphine tolerance and that both the development and expression of thermal hyperalgesia in morphine-tolerant rats are mediated by central NMDA and non-NMDA receptors and subsequent protein kinase $C$ (PKC) activation. Tolerance to the analgesic effect of morphine was developed in rats utilizing an intrathecal repeated treatment regimen. The development of morphine tolerance and thermal hyperalgesia was examined by employing the tail-flick test and paw-withdrawal test, respectively. Intrathecal MK 801 (an NMDA receptor antagonist), 6-cyano-7-nitroquinoxaline-2,3-dione (CNQX; a non-NMDA receptor antagonist), or GM1 ganglioside (an intracellular PKC inhibitor) treatment was given to examine the effects of these agents on the development and expression of thermal hyperalgesia in morphine-tolerant rats.

Tolerance to the analgesic effect of morphine was reliably developed in rats following once daily intrathecal (onto the lumbosacral spinal cord) injection of $10 \mu \mathrm{g}$ of morphine sulfate for 8 consecutive days as demonstrated by the decreased analgesia following morphine administration on day 8 as compared to that on day 1 . In association with the development of morphine tolerance, thermal hyperalgesia to radiant heat developed in these same rats. Paw-withdrawal latencies were reliably decreased in morphine-tolerant rats as compared to nontolerant (saline) controls when tested on day 8 before the last morphine treatment and on day 10 (i.e., $48 \mathrm{hr}$ after the last morphine treatment). The coincident development of morphine tolerance and thermal hyperalgesia was potently prevented by intrathecal coadministration of morphine with MK 801 (10 nmol) or GM1 (160 $\mathrm{nmol})$, and partially by CNQX (80 nmol). MK 801 (5, $10 \mathrm{nmol}$, not $2.5 \mathrm{nmol})$ and CNQX (80, $160 \mathrm{nmol}$, not $40 \mathrm{nmol})$, but not GM 1 ( $160 \mathrm{nmol}$ ), also reliably reversed thermal hyperalgesia in rats rendered tolerant to morphine when tested $30 \mathrm{~min}$ after each drug treatment on day 10 (48 hr after the last morphine treatment). The data indicate that thermal hyperalgesia develops in association with the development of

\footnotetext{
Received May 28, I993; revised Sept. 13, 1993; accepted Oct. 1, 1993.

We thank Juan Lu for her excellent technical assistance. This work was supported by U.S. Public Health Service Grant NS-24009 and a Grant-in-Aid from Virginia Commonwealth University.

Correspondence should be addressed to Jianren Mao, M.D., Ph.D., Department of Anesthesiology, Medical College of Virginia, P.O. Box 516, Richmond, VA 23298.

Copyright (C) 1994 Society for Neuroscience $0270-6474 / 94 / 142301-12 \$ 05.00 / 0$
}

morphine tolerance and that the coactivation of central NMDA and non-NMDA receptors is crucial for both the development and expression of thermal hyperalgesia in morphine-tolerant rats. Furthermore, intracellular PKC activation plays a critical role in the development of thermal hyperalgesia in morphinetolerant rats. Since NMDA and non-NMDA receptor activation is shown to play an important role in neurogenic and inflammatory hyperalgesia, the data suggest that common neural mechanisms may be involved in central hyperalgesic states across a variety of etiologies. The development of thermal hyperalgesia following repeated morphine administration suggests that there may be an interaction between the development of morphine tolerance and the associated hyperalgesia, a phenomenon that may have significant clinical implications for the treatment of painful conditions such as neuropathic pain, postoperative pain, and cancer pain.

[Key words: hyperalgesia, tolerance, dependence, morphine, excitatory amino acid receptors, MK 801, 6-cyano-7nitroquinoxaline-2,3-dione, GMt gangliosidel

Hyperalgesia, the enhanced nociceptive response to noxious stimulation, is associated with a variety of pathological conditions resulting from tissue injury including nerve injury (Dyck et al., 1984; Dubner, 1991a), surgical procedures (Dyck et al., 1984), peripheral inflammation (Ren et al., 1992a,b), and systemic metabolic disorders such as diabetes (Dyck et al., 1984). For instance, hyperalgesia is a known salient symptom of postinjury neuropathic pain syndromes (Bonica, 1979). However, hyperalgesic responses may also occur under circumstances that are not directly related to pathological ctiologics (Yaksh et al., 1986; Yaksh and Harty, 1988; Inoki et al., 1990; Ohnishi et al., 1990; Westbrook and Greeley, 1992). Recent investigations on narcotic dependence suggest that hyperalgesic responses to noxious stimulation may occur in rats undergoing naloxone-precipitated acute withdrawal (Bederson et al., 1990) as well as nonprecipitated withdrawal (Doerr and Kristal, 1991). These observations in addition to our own studies indicating a common neurochemical basis for opiate tolerance and neurogenic hyperalgesia (Mayer et al., 1993) suggest that hyperalgesia may develop in association with the development of tolerance to the analgesic effect of narcotics, a phenomenon that may have considerable clinical significance.

Recent evidence indicates that activation of excitatory amino acid (EAA) receptors, including the NMDA receptor and the non-NMDA (AMPA/kainate) receptor, is involved in the hyperalgesia that occurs following peripheral nerve injury (Davar et al., 1991; Mao et al., 1992b,f, 1993; Yamamoto and Yaksh, 
1992; Tal and Bennett, 1993) and inflammation (Ren et al., 1992a,b; Yamamoto et al., 1993). Systemic or spinal cord administration of NMDA and/or non-NMDA receptor antagonists potently reduces pain-related behaviors in animal models of neuropathic pain (Davar et al., 1991; Mao et al., 1992b,f, 1993; Yamamoto and Yaksh, 1992; Tal and Bennett, 1993), carrageenan-induced peripheral inflammation (Ren et al., 1992b; Yamamoto et al., 1993), and formalin-induced pain (Coderre and Melzack, 1991, 1992a,b). Moreover, the increase in intracellular protein kinase $\mathrm{C}$ (PKC) activity that occurs in response to NMDA receptor activation has been implicated in intracellular mechanisms of hyperalgesia, since GM1 ganglioside and $\mathrm{H}-7$, intracellular inhibitors of $\mathrm{PKC}$ translocation/activation, effectively attenuate hyperalgesia induced by peripheral nerve injury (Hayes et al., 1992; Mao et al., 1992c-e) or formalin injection into the rat's hind paw (Coderre, 1992). These converging lines of evidence indicate a critical role for central EAA receptor activation and subsequent intracellular PKC changes in CNS mechanisms of hyperalgesia.

Of relevant interest is that investigations on narcotic tolerance and dependence have indicated that the NMDA receptor activation also plays a critically important role in the development of narcotic tolerance and dependence, since MK 801, a noncompetitive NMDA receptor antagonist, has been shown to prevent the development of morphine tolerance and dependence in several experimental models (Marek et al., 1991a,b; Tanganelli et al., 1991; 'Irujillo and Akil, 1991; Ben Eliyahu et al., 1992). The site of the NMDA receptor activation is likely within the spinal cord, because spinalization does not reverse the inhibition of the development of morphine tolerance by systemic MK 801 administration (Gutstein et al., 1992). Given the importance of EAA receptors in neurogenic and inflammatory hyperalgesia, these data suggest that similar neural mechanisms may underlie both hyperalgesia resulting from a variety of pathological etiologies and narcotic tolerance/dependence. Thus, it is possible that the development and expression of hyperalgesia that may be associated with the development of narcotic tolerance and dependence are mediated by the central activation of NMDA and/or non-NMDA receptors as well as by subsequent intracellular events such as PKC activation. Accordingly, NMDA and/or non-NMDA receptor antagonists as well as intracellular inhibitors of PKC activation would be expected to prevent and reverse the hyperalgesia associated with the development of morphine tolerance/dependence.

In a rat model of narcotic tolerance and dependence utilizing an intrathecal treatment regimen, we tested the hypotheses that (1) hyperalgesia develops in association with the development of tolerance to the analgesic effect of morphine and (2) NMDA and non-NMDA receptor antagonists as well as PKC inhibitors prevent and reverse the hyperalgesia. The tail-flick and pawwithdrawal tests were used to assess the development of morphine tolcrance and hyperalgesia, respectively. Either MK 801, a noncompetitive NMDA receptor antagonist (Lodge and Johnson, 1990), 6-cyano-7-nitroquinoxaline-2,3-dione (CNQX), a non-NMDA (kainate/AMPA subtype) receptor antagonist (Lester et al., 1989), or GMl ganglioside, an intracellular inhibitor of PKC translocation/activation (Vaccarino et al., 1987; Costa and Rodbell, 1988; Favaron et al., 1988; Magal et al., 1990), was administered intrathecally along with morphine treatment to determine if each of these drugs would be able to prevent the development of both morphine tolerance and hyperalgesia. In addition, either MK 801, CNQX, or GM1 was given to rats rendered tolerant to morphine and undergoing a natural (nonprecipitated) withdrawal process to determine whether the hyperalgesia resulting from the development of morphine tolerance can be reversed by each drug treatment.

We report here that thermal hyperalgesia to radiant heat develops in rats in association with the development of morphine tolerance. In addition, both NMDA/non-NMDA receptors and $\mathrm{PKC}$ translocation/activation are involved in the development and expression of the thermal hyperalgesia.

\section{Materials and Methods}

\section{Subjects}

Adult male Sprague-Dawley rats (Hilltop) weighing 350-400 gm at the time of surgery were used. Animals were individually housed in cages with water and food pellets available ad libitum. The animal room was artificially illuminated from 07:00 to 19:00. All experimental procedures were approved by the Animal Care and Use Committee of the Medical College of Virginia, Virginia Commonwealth University.

\section{Intrathecal catheter implantation}

Each rat was implanted with an intrathecal catheter for drug or vehicle delivery. The intrathecal implantation procedure has been described in detail elsewhere (Mao et al., 1992f). In brief, rats were anesthetized intraperitoneally with sodium pentobarbital $(50 \mathrm{mg} / \mathrm{kg})$. A gentamicin sulfate-flushed polyethylene (PE-10) tube was inserted into the rat's subarachnoid space through an incision at the cisterna magna. The caudal end of the catheter was gently threaded to the site of spinal lumbosacral segments (about $7 \mathrm{~cm}$ from the incision) or thoracic segments (about $4.5 \mathrm{~cm}$ from the incision). The rostral end was then secured with dental cement to a screw embedded in the skull. The skin wound was closed with wound clips. Those rats exhibiting postsurgical neurological disorders (e.g., limb paralysis) were excluded from the experiment.

\section{Behavioral assessment}

The tail-flick test. The analgesic effect of morphine was evaluated by the tail-flick test as described previously (D'Amour and Smith, 1941; Akil and Mayer, 1972; Kellstein and Mayer, 1991). The rationale for using the tail-flick test to examine the development of morphine tolerance is that this test has been used extensively in studics of narcotic tolerance and dependence. In order to minimize handling and to facilitate both intrathecal drug delivery and tail-flick testing, each rat was comfortably positioned in a well-ventilated, tube-shaped plastic restrainer (internal diameter $6.5 \mathrm{~cm} \times$ internal length $25 \mathrm{~cm}$ ) with fore and hind paws extending through holes at the bottom of the restrainer. All animals were habituated to restraint $1 \mathrm{hr} / \mathrm{d}$ for $3 \mathrm{~d}$ prior to behavioral tests. The placement of a rat into the restrainer does not immobilize the rat. The rat can still move to a certain degree within the restrainer. In fact, rats usually voluntarily enter the tube-shaped restrainer during habituation and behavioral tests. No sign of distress was observed in these rats during restraint

The tail-flick latency was defined as the time from the onset of radiant heat to tail withdrawal. The radiant heat source was from a projection bulb underneath a $3-\mathrm{mm}$-thick glass plate. To test the tail-flick latency, the rat was placed on the glass plate. The radiant heat source was aimed at the caudal end (3-10 cm from the tail tip) of the rat's tail and adjusted by a rheostat to result in baseline (pretreatment) latencies of 3.5-4.5 sec. An automatic cutoff time of $10 \mathrm{sec}$ was preset to minimize tissue damage that may be caused by overstimulation in the absence of a response. Three trials were made with a $3 \mathrm{~min}$ intertrial interval and with changes of tail position receiving radiant heat stimulation on each trial. The mean tail-flick latency from the three trials was used as the baseline latency (BL). The analgesic effect of morphine was then determined by a single measurement of tail-flick latencies at 30,60,120, 180 , and $240 \mathrm{~min}$ after the morphine injection. Data were expressed in two ways: (1) absolute tail-flick latencies (TL) and (2) percentage of maximal possible analgesic effect (\%MPAE) using the equation \%MPAE $=[(T L-B L) /(10-B L)] \times 100$ as described previously $($ Kellstein and Mayer, 1991). 
The paw-withdrawal test. Thermal hyperalgesia to radiant heat was assessed by using the paw-withdrawal test (Bennett and Xie, 1988; Hargreaves et al., 1988; Mao et al., 1992b,f). The choice of the pawwithdrawal test to examine thermal hyperalgesia was based on the sensitivity of this test (Hargreaves et al., 1988). Although the tail-flick test is a reliable test to assess analgesia (increase in withdrawal latency above baseline), it is not sensitive for detection of hyperalgesia (dccreasc in withdrawal latency below baseline) because the baseline latency used for the tail-flick test is required to be quite low $(3-4 \mathrm{sec})$ for the test to remain valid. It should be pointed out that the only purpose of using the tail-flick test in these experiments was to allow an assessment of the development of tolerance to the analgesic effects of morphine using a commonly used and reliable methodology. Consistent with the previous finding that the paw-withdrawal test is sensitive to detect subtle changes in withdrawal latencies in response to radiant heat stimulation as compared to the tail-flick test (D'Amour and Smith, 1941; Akil and Mayer, 1972; Hargreaves et al., 1988; Kellstein and Mayer, 1991), data from our pilot experiment showed that the mean latency difference score between day 1 (baseline) and day 10 (48 hr after morphine withdrawal) in morphine-tolerant rats was $2.73 \pm 0.39 \mathrm{sec}$ using the paw-withdrawal test (student $t$ test, $P<0.01$ ) and $0.49 \pm 0.34 \mathrm{sec}$ using the tail-flick test (student $t$ test, $P>0.05$ ). Thus, the paw-withdrawal test was used in the present experiments to examine the development of thermal hyperalgesia because this test is more likely to detect increased responding (hyperalgesia) to radiant heat stimulation.

In order to obtain paw-withdrawal latencies, the rat was placed in a plastic cylinder (diameter $18 \mathrm{~cm} \times$ height $22 \mathrm{~cm}$ ) on a 3-mm-thick glass plate. The radiant heat source was from a projection bulb placed directly under the plantar surface of the rat's right hind paw. The paw-withdrawal latency to radiant heat stimulation was defined as the time from onset of radiant heat to withdrawal of the rat's hind paw. The radiant heat source was adjusted to result in baseline latencies of 11-13 sec. Three test trials (with an intertrial interval of $3 \mathrm{~min}$ ) were made for the rat's right hind paw, and scores from these three trials were averaged to yield a mean withdrawal latency. Thermal hyperalgesia was always tested prior to each morphine injection in the tolerance-inducing regimen whereas the tail-flick test was always made after each morphine injection.

\section{Drugs and intrathecal administration}

Drugs used in the experiments included morphine sulfate (10 $\mu \mathrm{g}), \mathrm{MK}$ 801 15-mcthyl-10,11-dihydro-5H-dibenzo(a,d)cyclohepten-5,10-imine maleate; 2.5, 5, 10 nmol], CNQX (6-cyano-7-nitroquinoxaline-2,3-dione; $40,80,160 \mathrm{nmol})$, and $\mathrm{GM} 1$ ganglioside $(160 \mathrm{nmol})$. Morphine sulfate and MK 801 were dissolved in saline solution, CNQX in sodium bicarbonate ( $\mathrm{pH} 7.5)$, and GM1 in phosphorate buffer solution ( $\mathrm{pH} 7.6)$. The intrathecal microinjection was performed using a $50 \mu 1$ microsyringe (Hamilton). Drugs or vehicle (in $10 \mu \mathrm{l}$ volume) used in the experiments were delivered slowly (within $1 \mathrm{~min}$ ) through the intrathecal catheter followed by $10 \mu \mathrm{l}$ of saline (void volume) to flush the catheter. When either MK 801 , CNQX, or GM1 was coadministered with morphine, the compounds were injected in the same bolus separated by an air bubble inside the tubing. All experiments described helow were made with the tester blind as to treatment conditions.

\section{Experimental designs}

Induction of morphine tolerance and thermal hyperalgesia. In order to induce tolerance to the analgesic effect of morphine, $10 \mu \mathrm{g}$ of morphine sulfate was given intrathecal onto the rat's spinal lumbosacral segments once daily for 8 consecutive days. The maximal possible analgesic effect of morphine was determined by examining the tail-flick latency both before (baseline) and after the first morphine $(10 \mu \mathrm{g})$ injection on day 1 of the treatment schedule. On day 8 (i.e., the last day of morphine treatment), the tail-flick latency was again tested following morphine $(10 \mu \mathrm{g})$ injection to examine the development of morphine tolerance. The rationale for using the $8 \mathrm{~d}$ treatment regimen and the test schedule (both on day 1 and day 8 ) was that this treatment regimen reliably induces morphine tolerance as described previously (Kellstein and Mayer, 1991). In addition, one group of rats $(n-6)$ received once daily saline treatment from day 1 to day 8 to examine whether the daily handling and the procedure of intrathecal treatment itself would have any effect on behavioral tests. Morphine was also given intrathecally onto spinal thoracic segments in one group of rats $(n=6)$ using the same dose regimen to control for possible effects of diffusion to supraspinal structures.

The development of thermal hyperalgesia was examined by testing the paw-withdrawal latency prior to morphine injection in the toleranceinducing regimen. The paw-withdrawal latency in rats was obtained before the first morphine injection on day 1 (baseline), on day 8 just before the last morphine injection, and on day $10(48 \mathrm{hr}$ after the last morphine treatment) to examine the development of thermal hyperalgesia. This test schedule allowed us to determine the development of thermal hyperalgesia both before (day 8) and after (day 10) the withdrawal from morphine treatment.

Prevention of the development of morphine tolerance and thermal hyperalgesia. In order to test the hypothesis that coadministration of morphine with MK 801, CNQX, or GM1 prevents the development of morphine tolerance and thermal hyperalgesia, five groups ( $n=6 /$ group) of rats were used. On day 1, tail-flick latencies were measured in each group of rats both before and after a single injection of $10 \mu \mathrm{g}$ of morphine to determine the maximal possible analgesic effect of morphine. Pawwithdrawal latencies were taken before the first morphine injection. From day 2 to day 7 , each group received one of the following treatments (once daily): (1) saline plus saline (nontolerant control), (2) saline plus morphine (tolerant control), (3) MK 801 (10 nmol) plus morphine, (4) CNQX $(80 \mathrm{nmol})$ plus morphine, and (5) GMl (160 nmol) plus morphine. Each treatment combination was coadministered through the intrathecal catheter (morphine followed by a drug). The effect of each treatment on the development of morphine tolerance was determined by the tail-flick test on day 8 after the last morphine ( $10 \mu \mathrm{g})$ injection, whereas the effect of each treatment on the development of thermal hyperalgesia was evaluated using the paw-withdrawal test both on day 8 before the last morphine injection and on day 10 (i.c., $48 \mathrm{hr}$ after the last morphine treatment). Three additional groups of rats ( $n=4$ /group) were used to control possible effects of repeated MK 801, CNQX, or GM1 itself on baseline tail-flick or foot-withdrawal latencies. Rats in each of the three groups received either saline plus MK $801(10 \mathrm{nmol})$, saline plus CNQX ( $80 \mathrm{nmol})$, or saline plus GM1 (160 nmol) using the same treatment regimen as described above and were tested on day 1 and day 8 .

Reversal of thermal hyperalgesia. The hypothesis that MK 801, CNQX, or GM1 reverses thermal hyperalgesia that presumably develops following the development of morphine tolerance was tested using 10 groups ( $n=6 /$ group) of rats including three saline groups and seven morphine treatment groups. The saline groups were used to serve as nontolerant controls as described above. Thus, morphine tolerance was first induced in seven groups of rats utilizing the same treatment regimen as that described above and the development of thermal hyperalgesia was examined on day 10 of the treatment schedule, that is, $48 \mathrm{hr}$ after the last morphine administration. The rationale for choosing this particular time point to examine the reversal of thermal hyperalgesia was that the withdrawal signs and symptoms, including body weight loss, writhing, and aggression, peak at about $24-48 \mathrm{hr}$ after abstinence from morphine (Ehrenpreis and Neidle, 1975; Bederson et al., 1990; Doerr and Kristal, 1991). Either MK 801 (2.5, 5, $10 \mathrm{nmol})$, CNQX (40, 80, $160 \mathrm{nmol})$, or GM1 (160 nmol) was then delivered intrathecally to each group of rats on day 10 after the evaluation of thermal hyperalgesia. Thirty minutes after each drug treatment, the paw-withdrawal latency was again tested to examine if the drug reversed thermal hyperalgesia. MK $801(10 \mathrm{nmol})$, CNQX (160 nmol), or GMI (160 nmol) also was delivered to each of three saline control groups and paw-withdrawal latencies were measured $30 \mathrm{~min}$ after each injection to examine the effect of MK 801, CNQX, and GM1 per se on paw-withdrawal latencies.

\section{Statistical data analyses}

Data from the tail-flick test were calculated by using the equation \%MPAE $=[(\mathrm{TL}-\mathrm{BL}) /(10-\mathrm{BL})] \times 100$ to yield the mean percentage of maximal possible analgesic effects. Both tail-flick data (the calculated \%MPAE and absolute tail-flick latencies) and absolute paw-withdrawal latencies were analyzed by using a two-way analysis of variance (ANOVA) repeated across testing points to detect overall differences among treatment groups. Whenever applicable, data from the tail-flick or pawwithdrawal test also were examined using ANOVA repeated across treatment groups to examine overall differences among testing points. In both cases, when main effects were observed, the Waller-Duncan $K$-ratio $t$ test (WD) was performed to determine sources of differences. Differences were considered to be statistically significant at the level of $\alpha=0.05$. 

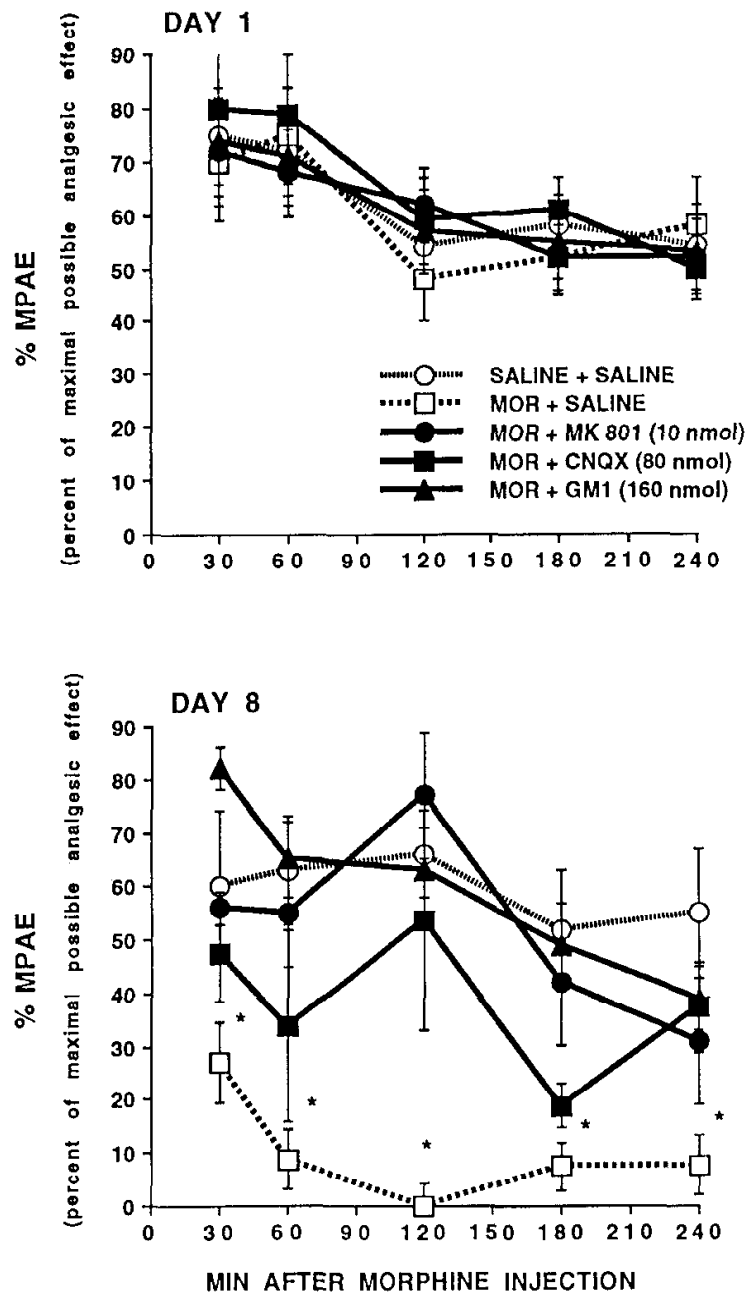

Figure 1. MK 801, CNQX, or GM1 ganglioside prevented the development of morphine tolerance. In all five groups, percentage of maximal possible analgesic effect ( $\% M P A E)$ was not different on day 1 following intrathecal injection of $10 \mu \mathrm{g}$ of morphine sulfate as tested using the tail-flick test (Day 1). Day 8 shows group differences in morphine tolerance resulting from different treatments. Each group of rats received $10 \mu \mathrm{g}$ of morphine on day 1 and day 8 . Between day 2 and day 7 , each group of rats received either saline (saline + saline) or one of the drug treatments. Once daily intrathecal administration of $10 \mu \mathrm{g}$ of morphine sulfate $(M O R)$ and saline for 8 consecutive days induced tolerance to the analgesic effect of morphine as indicated by reliable decreases in \%MPAE in the morphine plus saline group as compared to the same group on day 1 and to those rats in the saline group. In contrast, rats coadministered with $10 \mu \mathrm{g}$ of morphine and MK 801 (10 nmol), CNQX $(80 \mathrm{nmol})$, or GMl $(160 \mathrm{nmol})$ between day 2 and day 7 showed reliably higher \%MPAE (i.e., analgesia) as compared to the morphine and saline group. Data at each testing point represent the mean of a group of six rats. Standard errors are given hy error bars. ${ }^{*}, P<0.05$ (WD), comparisons made between the morphine and saline group and each morphine and drug treatment group.

\section{Results}

Thermal hyperalgesia developed in rats in association with the development of morphine tolerance. The development of both morphine tolerance and thermal hyperalgesia was effectively prevented by MK 801 or GM1, and partially by CNQX. MK 801 or CNQX, but not GM1, also potently reversed thermal hyperalgesia in morphine-tolerant rats.
Thermal hyperalgesia developed in association with the development of morphine tolerance

Once daily intrathecal injection of $10 \mu \mathrm{g}$ of morphine for 8 consecutive days induced tolerance to the analgesic effect of morphine in rats. On day 1 , the analgesia produced by intrathecal injection of $10 \mu \mathrm{g}$ of morphine was equivalent among groups as indicated by the lack of statistical differences in both absolute tail-flick latencies (Table 1) and the mean percentage of maximal possible analgesic effect (\%MPAE) (Fig. 1, Day 1). In contrast to those rats receiving saline treatment between day 2 and day 7 (but $10 \mu \mathrm{g}$ of morphine on day 1 and day 8), which showed no statistical difference in \%MPAE between day 1 and day 8 (ANOVA, $P>0.05$ ), both absolute tail-flick latencies (Table 1) and \%MPAE (Fig. 1, Day 8) were reliably lowered in the morphine plus saline group as compared to those of the same group on day 1 (Fig. 1, Day 1) and to those in the saline group on the same day (Fig. 1, Day 8; WD, each $P<0.0 .5$ ). The decrease in the analgesic effect of morphine was not due to nonspecific effects such as daily handling and the procedure of repeated treatment on tail-flick latencies, because tail-flick latencies were not different between day 1 and day 8 (day $1,4.3 \pm 0.6 \mathrm{sec}$, vs day $8,4.4 \pm 0.7 \mathrm{sec}$; ANOVA, $P>0.05$ ) in rats treated only with saline from day 1 to day 8 , the group that never received morphine treatment.

In association with the development of morphine tolerance, demonstrable thermal hyperalgesia was observed in rats given once daily morphine plus saline treatment, as indicated by mean paw-withdrawal latencies at various time points (Table 2). This decrease in paw-withdrawal latencies was observed both on day 8 before the last morphine treatment and on day 10 ( $48 \mathrm{hr}$ after the last morphine treatment). Compared with paw-withdrawal latencies taken before the first morphine treatment on day 1 (baseline), which showed no reliable differences among all treatment groups (Table 2; ANOVA, $P>0.05$ ), paw-withdrawal latencies were reliably decreased in morphine-tolerant rats when tested on day 8 before the last morphine injection and on day 10 of the experimental schedule (Table 2; WD, each $P<0.05$ ). In contrast, no reliable differences in paw-withdrawal latencies were observed between day 1 (baseline), day 8 , and day 10 in rats receiving saline treatment (days 2-7) and $10 \mu \mathrm{g}$ of morphine on day 1 and day 8 (Table 2; ANOVA, $P>0.05$ ), as well as in rats treated only with saline from day 1 to day 8 (day $1,11.1$ $\pm 0.6 \mathrm{sec}$; day $8,10.9 \pm 0.7 \mathrm{sec}$; day $10,11.0 \pm 0.8 \mathrm{sec}$; ANOVA, $P>0.05$ ).

Neither tail-flick (day 1, $4.2 \pm 0.8 \mathrm{sec}$, vs day $8,4.5 \pm 0.7$ $\mathrm{sec}$ ) nor paw-withdrawal latencies (day $1,11.5 \pm 0.7 \mathrm{sec}$, vs day $8,11.0 \pm 0.8 \mathrm{sec}$ ) were statistically different (ANOVA, each $P$ $>0.05)$ in rats before and after the repeated thoracic morphine treatment employing the same treatment schedule used in lumbosacral treatment groups, indicating an effect localized to the lumbosacral spinal cord of repeated morphine treatment on the development of morphine tolerance and thermal hyperalgesia.

\section{Effect of $M K 801, C N Q X$, and GMI on development of morphine tolerance and thermal hyperalgesia}

Intrathecal coadministration of morphine with MK 801, CNQX, or GM1 effectively prevented the development of morphine tolerance. In comparison with the rats treated with morphine and saline, which showed almost complete tolerance to the analgesic effect of morphine on day 8 (Fig. 1), rats receiving coadministration of morphine with MK 801 (10 nmol), CNQX (80 
Table 1. Development of morphine tolerance

\begin{tabular}{|c|c|c|c|c|}
\hline & \multicolumn{4}{|c|}{ Mean absolute tail-flick latencies (sec) } \\
\hline & \multicolumn{2}{|l|}{ Day 1} & \multicolumn{2}{|l|}{ Day 8} \\
\hline & Before MOR & After MOR & Before MOR & After MOR \\
\hline Saline + saline & $4.3 \pm 0.7$ & $8.0 \pm 0.6^{*}$ & $4.4 \pm 0.7$ & $7.8 \pm 0.7^{*}$ \\
\hline Morphine + saline & $4.1 \pm 0.5$ & $7.7 \pm 0.5^{*}$ & $4.2 \pm 0.6$ & $4.8 \pm 0.5$ \\
\hline Morphine + saline (thoracic) & $4.0 \pm 0.6$ & $4.0 \pm 0.6$ & $3.9 \pm 0.5$ & $3.8 \pm 0.6$ \\
\hline Morphine + MK $801(10 \mathrm{nmol})$ & $4.2 \pm 0.7$ & $7.9 \pm 0.6^{*}$ & $3.9 \pm 0.5$ & $7.2 \pm 0.7^{*}$ \\
\hline Morphine + CNQX (80 nmol) & $3.9 \pm 0.4$ & $7.9 \pm 0.5^{*}$ & $4.4 \pm 0.7$ & $6.6 \pm 0.5^{*}$ \\
\hline Morphine + GM1 (160 nmol) & $4.2 \pm 0.6$ & $7.9 \pm 0.5^{*}$ & $4.0 \pm 0.5$ & $7.6 \pm 0.7^{*}$ \\
\hline
\end{tabular}

Data are presented as mean $\pm \mathrm{SE}$, and refer to mean absolute tail-flick latencies before and after (averaged from tailflick latencies measured at $30,60,120,180$, and 240 min after treatment) a single intrathecal morphine (MOR; $10 \mu \mathrm{g})$ injection on day 1 and day 8 . Between day 2 and day 7 , each group of rats received either saline or one of the drug treatments.

${ }^{*} p<0.05$ (WD) as compared to tail-flick latencies before morphine injection in each corresponding group.

nmol), or GMl (160 nmol) between day 2 and day 7 remained analgesic following the last morphine injection on day 8 of the treatment schedule (Fig. 1; WD, each $P<0.05$ ). The remaining analgesia on day 8 in the MK 801, CNQX, and GM1 treatment groups was unlikely to be caused by the effect of repeated MK 801 , CNQX, or GM1 treatment per se on tail-flick latencies, because tail-flick latencies (as well as paw-withdrawal latencies) were not different between day 1 and day 8 (ANOVA, $P>0.05$ ) in rats repeatedly treated with saline plus either MK 801 (10 nmol), CNQX (80 nmol), or GM1 (160 nmol). In addition, tailflick latencies pooled from those rats treated with morphine plus either MK 801, CNQX, or GM1 were not statistically different from rats in the saline plus morphine group (saline plus morphine group, $4.4 \pm 0.7 \mathrm{sec}$, vs drug groups, $4.2 \pm 0.9 \mathrm{sec}$; ANOVA, $P>0.05$ ) when both were tested on the same day (day 8 ) before the last morphine injection.

Consistent with the prevention of morphine tolerance by MK 801 and GM1, the development of thermal hypcralgesia also was prevented in rats cotreated with morphine and MK 801 or GM1 as indicated by the lack of observed differences in pawwithdrawal latencies between day 1 (baseline), day 8 (the last day of morphine treatment), and day 10 (48 hr after the last morphine treatment) in these rats (Table 2; ANOVA, $P>0.05$ ) and by reliably higher paw-withdrawal latencies in these rats than in rats cotreated with morphine and saline (Table 2; WD, each $P<0.05$ ). While $80 \mathrm{nmol}$ of CNQX was shown to prevent (at least partially) the development of morphine tolerance (Fig. 1), this same dose of CNQX failed to prevent the development of thermal hyperalgesia as indicated by reliably shorter pawwithdrawal latencies in these rats both on day 8 and on day 10 as compared to those on day 1 (Table 2 ; WD, $P<0.05$ ). However, as also shown in Table 2 , the mean decrease in pawwithdrawal latencies (paw-withdrawal latencies on day 1 minus those on day 8 or day 10) was much greater in the saline plus morphine treatment group (day $8,3.4 \mathrm{sec}$; day $10.3 .8 \mathrm{sec}$ ) than in the CNQX plus morphine treatment group (day 8, $2.1 \mathrm{sec}$; day $10,2.4 \mathrm{sec}$; Student's $t$ test, each $P<0.05$ ), indicating a partial prevention of the development of thermal hyperalgesia by $80 \mathrm{nmol}$ CNQX treatment.

\section{Effect of $M K 801, C N Q X$, and GMI on reversal of thermal hyperalgesia in morphine-tolerant rats}

As shown in Figures 2-4, reliable decreases in paw-withdrawal latencies (i.e., thermal hyperalgesia) were observed in all groups of rats repeatedly treated with morphine when tested on day 10 (48 hr after the last morphine treatment). This thermal hyperalgesia was reliably reversed in a dose-dependent manner by intrathecal treatment with MK 801 or CNQX. Thus, mean pawwithdrawal latencies were reliably increased in these rats when tested $30 \mathrm{~min}$ following a single treatment with MK 801 (10 $\mathrm{nmol}=5 \mathrm{nmol}$, but not $2.5 \mathrm{nmol})$ or CNQX $(160 \mathrm{nmol}=80$ nmol, but not $40 \mathrm{nmol}$ ) as compared to corresponding mean paw-withdrawal latencies before each treatment (Figs. 2, 3, WD, each $P<0.05$ ). While $160 \mathrm{nmol}$ of GM1 effectively prevented the development of both morphine tolerance (Fig. 1) and thermal hyperalgesia (Table 2), this same dose of GM1 failed to

Table 2. Prevention of thermal hyperalgesia

\begin{tabular}{llcc} 
& \multicolumn{3}{l}{ Paw-withdrawal latencies (sec) } \\
\cline { 2 - 4 } & Day 1 & Day 8 & Day 10 \\
\hline Saline + saline & $11.2 \pm 0.8$ & $10.7 \pm 0.6$ & $10.9 \pm 0.5$ \\
Morphine + saline & $11.7 \pm 1.0$ & $8.3 \pm 0.6^{*}$ & $7.9 \pm 0.5^{*}$ \\
Morphine + saline (thoracic) & $11.5 \pm 0.7$ & $11.0 \pm 0.8$ & $10.9 \pm 0.7$ \\
Morphine + MK 801 (10 nmol) & $10.9 \pm 0.6$ & $10.7 \pm 0.6$ & $10.3 \pm 0.4$ \\
Morphine + CNQX (80 nmol) & $10.8 \pm 0.7$ & $8.7 \pm 0.4^{*}$ & $8.4 \pm 0.3^{*}$ \\
Morphine + GM1 (160 nmol) & $11.3 \pm 0.6$ & $10.5 \pm 0.7$ & $10.1 \pm 0.8$ \\
\hline
\end{tabular}

Data are presented as mean $\pm \mathrm{SE}$, and were obtained on day 1 (baseline), day 8 (before the last morphine treatment), and day 10 (48 hr after the last morphine treatment). Each group of rats received $10 \mu \mathrm{g}$ of morphine on day 1 and day 8. Between day 2 and day 7 , each group of rats received either saline or one of the drug treatments.

${ }^{*} p<0.05$ (WD) as compared to baseline paw-withdrawal latencies of each corresponding group on day 1 . 


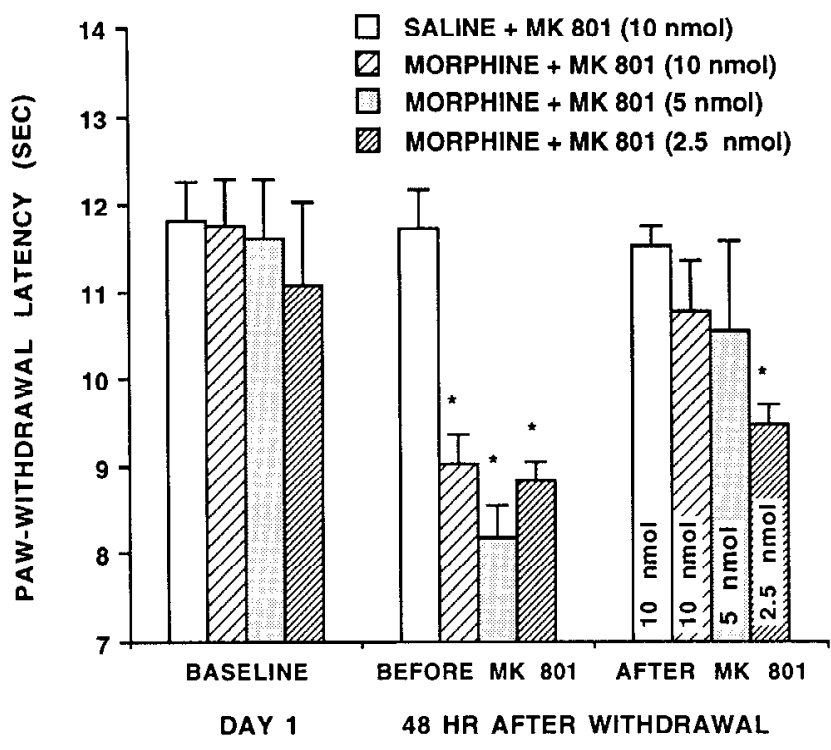

Figure 2. MK 801 reversed NITH in morphine-tolerant rats. In contrast to paw-withdrawal latencies taken before the first morphine injection (baseline), which showed no statistical difference among groups, paw-withdrawal latencies were reliably decreased (i.e., hyperalgesia) in rats receiving repeated $10 \mu \mathrm{g}$ morphine treatment as compared to those receiving saline treatment and compared to their own corresponding baseline paw-withdrawal latencies. A single intrathecal treatment with MK 801 ( 5 or $10 \mathrm{nmol}$, not $2.5 \mathrm{nmol}$ ) at $48 \mathrm{hr}$ after withdrawal from morphine reversed thermal hyperalgesia when tested $30 \mathrm{~min}$ after MK 801 treatment. MK $801(10 \mathrm{nmol})$ did not change baseline paw-withdrawal latencies as indicated by the lack of observed decreases in pawwithdrawal latencies in the saline group when tested $30 \mathrm{~min}$ after MK 801 treatment on day 10 . Standard errors are given by the error bars. ${ }^{*}, P<0.05$ (WD), as compared to the saline group on the same day.
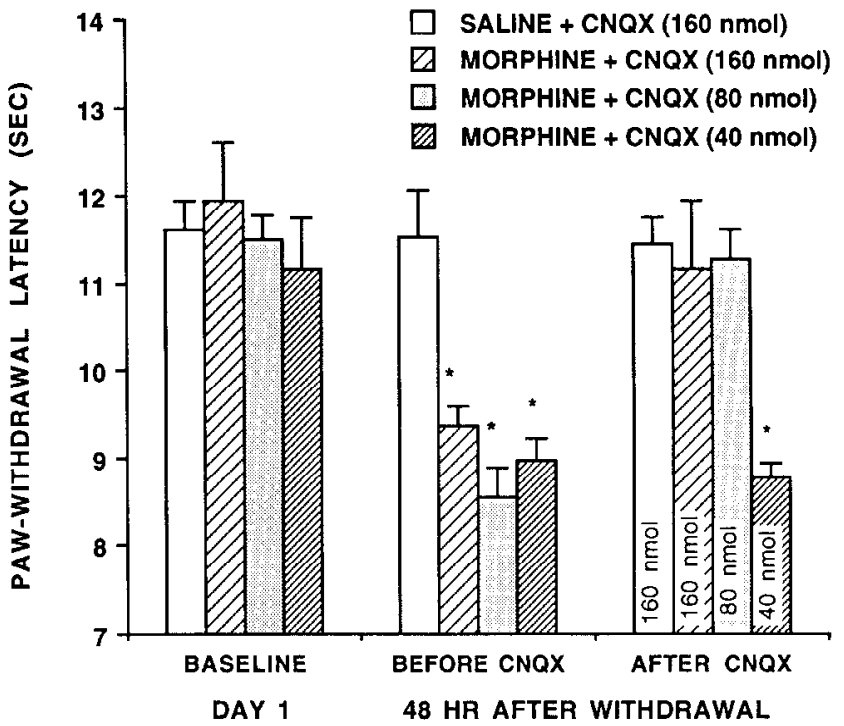

Figure 3. CNQX reversed NITH in morphine-tolerant rats. In contrast to paw-withdrawal latencies taken before the first morphine injection (baseline), which showed no statistical difference among groups, pawwithdrawal latencies were reliably decreased (i.e., hyperalgesia) in rats receiving repeated $10 \mu \mathrm{g}$ morphine treatment as compared to those receiving saline treatment and compared to their own corresponding baseline paw-withdrawal latencies. A single intrathecal treatment with CNQX ( 80 or $160 \mathrm{nmol}$, not $40 \mathrm{nmol}$ ) at $48 \mathrm{hr}$ after withdrawal from morphine reversed thermal hyperalgesia when tested $30 \mathrm{~min}$ after CNQX treatment. CNQX (160 nmol) did not change baseline paw-withdrawal latencies as indicated by the lack of observed decreases in paw-withdrawal latencies in the saline group when tested $30 \mathrm{~min}$ after CNQX treatment on day 10 . Standard errors are given by the error bars. ${ }^{*}, P$ $<0.05$ (WD), as compared to the saline group on the same day. reverse thermal hyperalgesia that had already been developed in morphine-tolerant rats as indicated by the lack of reliable differences in paw-withdrawal latencies in this group of rats before and $30 \mathrm{~min}$ after intrathecal administration of $160 \mathrm{nmol}$ of GM1 (Fig. 4; ANOVA, $P>0.05$ ).

Neither MK 801 (10 nmol), CNQX (160 nmol), nor GMl $(160 \mathrm{nmol})$ altered paw-withdrawal latencies of saline-treated rats as indicated by the lack of observed differences in these rats on day 10 before and after administration of each of these drugs (Figs. 2-4; ANOVA, $P>0.05$ ).

\section{Discussion}

The major findings of the present experiments are that thermal hyperalgesia developed in association with the development of tolerance to the analgesic effect of morphine in rats, and that both the development of morphine tolerance and thermal hyperalgesia were potently prevented by MK 801 (an NMDA receptor antagonist) or GM1 ganglioside (an intracellular inhibitor of PKC translocation/activation), and partially prevented by CNQX (a non-NMDA receptor antagonist). MK 801 and CNQX, but not GM1, also powerfully reversed thermal hyperalgesia in morphine-tolerant rats. The results indicate a critically important role of central NMDA and non-NMDA receptor activation and subsequent intracellular PKC activation in the development and/or expression of thermal hyperalgesia associated with the development of morphine tolerance. We call this thermal hyperalgesia "narcotic-induced thermal hyperalgesia" (NITH) in order to distinguish it from neurogenic (induced by nerve injury) and inflammatory (following tissue inflammation) hyperalgesia. Since NMDA and non-NMDA receptor activation also is involved in neurogenic (Davar et al., 1991; Mao et al., 1992b,f, 1993; Yamamoto and Yaksh, 1992; Tal and Bennett, 1993) and inflammatory (Ren et al., 1992a,b; Yamamoto et al., 1993) hyperalgesia, the present data suggest that common neural mechanisms may be involved in CNS hyperalgesic states across a variety of etiologies. The possible relationships of neural mechanisms involved in the development of morphine tolerance and the associated NITH as well as the clinical implications of these relationships will be discussed.

\section{Development of NITH in association with the development of morphine tolerance}

Hyperalgesic responses to noxious stimulation have been observed in rats undergoing naloxone-precipitated acute withdrawal from morphine (Bederson et al., 1990) or during the course of abstinence from morphine in narcotic-tolerant rats (Doerr and Kristal, 1991). In fact, hyperalgesia is thought to be a sign of physical dependence on narcotic analgesics (Ehrenpreis and Neidle, 1975; Bederson et al., 1990; Doerr and Kristal, 1991). Consistent with these early observations, in the present experiments thermal hyperalgesia developed in morphine-tolerant rats as shown by the reliable decrease in paw-withdrawal latencies in these rats both on day 8 before the last morphine treatment and on day 10 , that is, $48 \mathrm{hr}$ after the last morphine 
treatment (see Table 2). It should be emphasized, however, that thermal hyperalgesia was observed in the present study during a natural (non-naloxone precipitated) withdrawal process. To our knowledge, this is the first observation that thermal hyperalgesia occurs during nonprecipitated narcotic withdrawal in a rat model of repeated intrathecal morphinc administration.

Data derived from the present study clearly indicate that the observed NITH developed in association with the development of morphine tolerance because MK 801 or GM1 potently prevented the development of both morphine tolerance and NITH when coadministered with morphine between day 2 and day 7 of the treatment schedule. It is, however, not yet clear to us whether NITH observed in this model truly reflects a sign of physical dependence similar to those seen in the narcotic withdrawal process (Ehrenpreis and Neidle, 1975; Doerr and Kristal, 1991). For instance, while both NITH and signs of physical dependence such as wet-dog shaking, weight loss, and ptosis (Ehrenpreis and Neidle, 1975) can be observed at 24 and $48 \mathrm{hr}$ after the last morphine administration, the degree of NITH was not different between day 8 before the last morphine treatment and day 10 at $48 \mathrm{hr}$ after the last morphine administration in our expcriments (see Table 2). In contrast, signs of physical dependence appear to progress as a function of the time course of narcotic withdrawal, particularly during the first few days after abstinence from narcotics (Ehrenpreis and Neidle, 1975). In addition, in the present study a single injection of MK 801 , a noncompetitive NMDA receptor antagonist, potently reversed NITH on day 10 , whereas in a model of systemic morphine administration a single injection of MK 801 failed to stop jumping (a sign of physical dependence) in morphine-tolerant rats undergoing the naloxone-precipitated withdrawal process (Trujillo and Akil, 1991). Such a difference may be in part due to the differential roles of NMDA receptors in NITH and jumping.

It should be noted that the development of NITH in this intrathecal treatment model was not due to drug diffusion to supraspinal structures via either the vasculature or the cerebrospinal fluid, because repeated intrathecal morphine administration onto the thoracic spinal cord failed to affect tail-flick and hind paw-withdrawal latencies in these rats. Thus, the development of NITH is most likely to be mediated by local neural mechanisms within the spinal cord. This may partially explain the differences between the observed NITH and signs of physical dependence in which different treatment routes were used, that is, intrathecal (in the present experiment) versus systemic (in previous experiments) morphinc administration (Ehrenpreis and Neidle, 1975; Doerr and Kristal, 1991). In addition, it is unlikely that the development of morphine tolerance and NITH in the present experiment is due to the procedure of repeated administration and handling over $8 \mathrm{~d}$ in which associative learning has been suggested to play a role (Baker and Tiffany, 1985; Siegel, 1988), because saline-treated rats handled in the same manner as morphine-treated rats showed no changes in either tail-flick or paw-withdrawal latencies over the experimental period. Finally, it is important to point out that although we observed reliable thermal hyperalgesia using the paw-withdrawal test and not the tail-flick test, the possible contribution of the development of thermal hyperalgesia to decreased tail-flick latencies (i.e., tolerance) on day 8 in morphine-tolerant rats cannot be ruled out. In other words, the behavioral manifestation of morphine tolerance as demonstrated using the tail-flick test may reflect the development of both hyperalgesia and attenuated opiate analgesia.

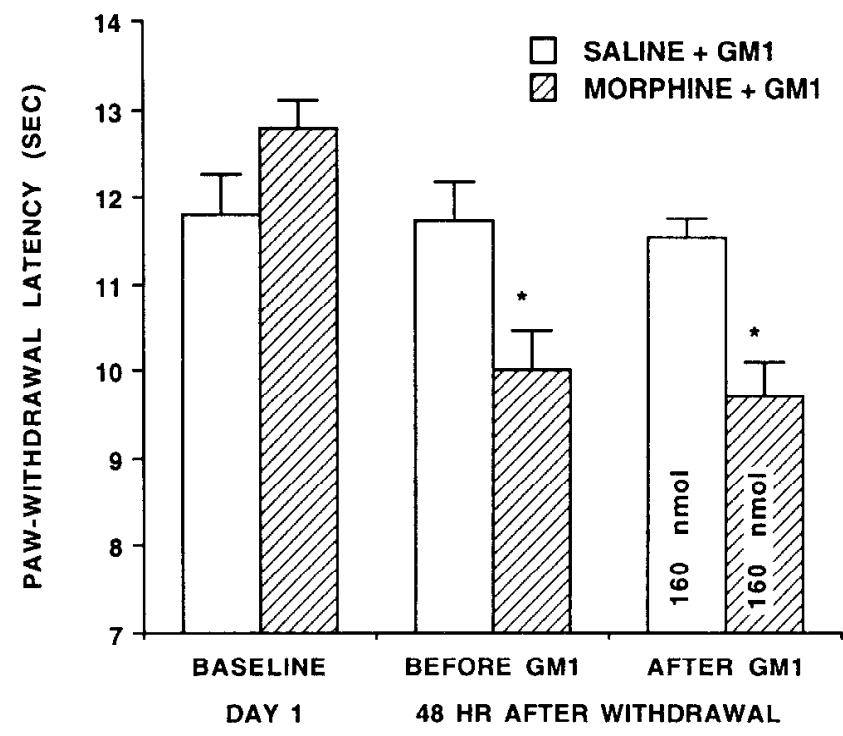

Figure 4. GMI ganglioside failed to reverse NITH in morphine-tolerant rats. A single intrathecal treatment with GM1 (160 nmol), the dose that potently prevented the development of tolerance and thermal hyperalgesia, failed to reverse hyperalgesia in morphine-tolerant rats when tested $30 \mathrm{~min}$ after GM1 treatment on day 10 , that is, $48 \mathrm{hr}$ after withdrawal from the last morphine treatment. When tested $30 \mathrm{~min}$ after the treatment on day 10, GM1 ganglioside also did not change pawwithdrawal latencies obtained on day $I$ before the first morphine injection (baseline). Standard errors are given by the error bars. ${ }^{*}, P<$ 0.05 (WD), as compared to the saline group on the same day.

\section{Contribution of NMDA and non-NMDA receptors to the development and expression of NITH}

Since NITH develops in association with the development of morphine tolerance, it is reasonable to ask how repeated morphine administration can result in the development of NITH as well as morphine tolerance. Recent behavioral studies have indicated a critical role for the NMDA receptor in the development of morphine tolerance and dependence (Marek et al., 199 la,b; Tanganelli et al., 1991; Trujillo and Akil, 1991; Ben Eliyahu et al., 1992). The site of the NMDA receptor action is likely within the spinal cord since spinalization does not diminish the preventive effect of systemic MK 801 on the development of morphine tolerance (Gutstein et al., 1992). Data derived from the present experiments further indicate that intrathecal coadministration of MK $801(10 \mathrm{nmol})$ with morphine powerfully prevented the development of both morphine tolerance and NITH. Moreover, our data indicate, for the first time, that CNQX (a non-NMDA receptor antagonist, $80 \mathrm{nmol}$ ) prevented at least partially the development of morphine tolerance (see Fig. 1) and partially prevented the development of NITH (see Table 2). In addition, a single treatment with MK 801 (10 or 5 , not $2.5 \mathrm{nmol}$ ) or CNQX (160 or 80 , not $40 \mathrm{nmol}$ ) on day 10 potently reversed NITH that has been established following the repeated morphine administration, indicating that NMDA and non-NMDA receptors are important in the expression of NITH as well. Taken together, these data clearly indicate that spinal cord NMDA and non-NMDA receptors play a critical role in both the development and expression of NITH.

Although it is evident that spinal cord NMDA and non-NMDA receptors become involved in the development and expression of NITH, it is perplexing as to how NMDA and non-NMDA receptors participate in this neural process because exogenous 
morphine activates opiate but not NMDA/non-NMDA receptors. This remains an open question and has not yet been investigated in any depth. Two general possibilities may be considered by which the NMDA and non-NMDA receptors may become involved in the development of NITH and morphine tolerance: (1) configurational similarities/changes may occur between NMDA/non-NMDA receptors and opiate receptors, and (2) endogenous agonists, namely, glutamate and aspartate, may be released during the development of morphine tolerance and activate NMDA/non-NMDA receptors.

The hypothesis of configurational similarity/change is that there might be some configurational similarities between the opiate $(\mu)$ receptor and the NMDA and non-NMDA reccptors such that exogenous morphine could activate the NMDA and non-NMDA receptors to a certain degree, or the activation of the opiate $(\mu)$ receptor could somehow modulate NMDA and non-NMDA receptor activity within the same neuron through configurational alterations and/or second messenger systems. In turn, configurational changes in NMDA/non-NMDA receptors may result in increases in their activity and decreases in opiate receptor responsiveness via membrane receptor interchanges and/or intracellular modulations of both types of receptors. For example, configurational or second messenger-mediated changes in the NMDA receptor following exogenous morphine treatment might result in the opening of the $\mathrm{Ca}^{2+}$ channel and induce subsequent intracellular changes. This possibility seems to be supported by a recent study that shows that activation of the $\mu$ opiate receptor may modulate the NMDA receptor via intracellular PKC activation (Chen and Huang, 1991). Additional indirect evidence for this possibility is that MK 801, an NMDA receptor antagonist, differentially regulates the effects of opiate receptor subtypes (Kest et al., 1992). While MK 801 potently prevents morphine-induced tolerance (primarily acting on the $\mu$ opiate receptor) without affecting the acute antinociceptive effects of morphine, it directly blocks the antinociceptive effect of $\mathrm{U} 50,488 \mathrm{H}$, a selective $\kappa$ opiate receptor agonist (Kest et al., 1992), suggesting that the differential effects of MK 801 may be related to configurational differences of the opiate receptor subtypes. However, the configurational similarity/change hypothesis is not readily supported by any known properties of the opiate $(\mu)$ receptor and the NMDA and non-NMDA receptors. In addition, based on this hypothesis it is difficult to explain why the blockade of the non-NMDA ionotropic receptor prevents the development of NITH and morphine tolerance in a manner similar to that induced by the NMDA receptor antagonist.

The second hypothesis is that the NMDA and non-NMDA receptors may be activated by their endogenous agonists (EAAs) over the period of repeated morphine administration. Given the fact that NMDA and non-NMDA receptor antagonists reliably block the development of morphine tolerance and NITH, this appears to be a distinct possibility. However, if this is the case, then where and how is EAA released as a result of exogenous opiate administration? There are three possible routes by which EAA may be released: (1) from primary afferents, (2) from supraspinal descending pathways, and (3) from spinal cord interneurons.

Primary afferents. EAAs are released from primary afferents, particularly of $\mathrm{A} \hat{o}$ and $\mathrm{C}$ fibers, upon peripheral stimulation (Wilcox, 1991). Exogenous morphine may regulate the release of neurotransmitters/neuromodulators including EAAs from the primary afferents through presynaptic opiate receptors (Tung and Yaksh, 1982; Seybold, 1986). However, it is recognized that primary afferents, particularly $\mathrm{A} \delta$ and $\mathrm{C}$ fibers, exhibit very little spontaneous discharge (Price, 1988). Thus, there appears to be a minimal basis for the regulation of EAA release from primary afferents following exogenous opiate treatment.

Supraspinal descending pathways. Supraspinal descending pathways modulate spinal cord neuronal activity (Willis, 1985; Price, 1988), and it is not unlikely that some of these descending pathways may utilize an EAA as their neurotransmitter/neuromodulator. Thus, chronic morphine treatment may somehow activate these descending pathways via ascending and descending interconnections with the resultant release of EAA from their nerve terminals. However, two experimental observations secm to suggest a minimal involvement of supraspinal structures in this neural process. One is a previous report that indicates that the preventive effects of systemic MK 801 on morphine tolerance is not diminished when given at $7 \mathrm{~d}$ after spinalization (Gutstein et al., 1992). The other is our present observation that shows that the development of morphine tolerance and NITH as assessed using tail-nick and hind paw withdrawal tests was induced by intrathecal morphine administration onto the lumbosacral but not the thoracic spinal cord. Nevertheless, it remains to be determined whether supraspinal descending pathways contribute to spinal cord NMDA/non-NMDA receptor activation in intact animal preparations and in models of systemic narcotic treatment.

Spinal cord interneurons. Given that the highest density of receptor binding sites of both opiate and EAA receptors is in the superficial laminae (lamina II > lamina I) of the mammalian spinal cord dorsal horn (Seybold, 1986; Mitchell and Anderson, 1991), a neural circuit may exist within this area of the spinal cord involving both excitatory and inhibitory interneurons. The inhibition of spinal cord inhibitory interneurons (e.g., GABA interneurons) induced by the direct effect of morphine may result in disinhibition of EAA-containing interneurons with the resultant release of EAA into the spinal cord. However, it is not known whether (1) there are indeed EAA-containing interneurons within the spinal cord dorsal horn or (2) exogenous morphine can release (excite) neurons by means of disinhibition.

Another problem with this EAA agonist hypothesis regardless of the source of endogenous EAA is that reduction of the $\mathrm{Mg}^{2+}$ blockade of the NMDA receptor by partial depolarization of the neuronal membrane appears difficult under the inhibitory influence of morphine. One possible means by which morphineinduced inhibition may be overcome is the coactivation of the non-NMDA receptor with the NMDA receptor. The $\mathrm{Mg}^{2+}$ blockade may be removed by partial membrane depolarization induced by non-NMDA receptor activation when such partial depolarization is temporally associated with NMDA receptor activation and is spatially adjacent to the membrane NMDA receptor. Our present observation that the antagonism of nonNMDA receptors also effectively prevents the devclopment of morphine tolerance and, at least in part, the associated NITH seems to support this possibility. Other excitatory neuromodulators such as cholecystokinin, likely to be released through the same mechanism of disinhibition, may also facilitate NMDA receptor activation through partial depolarization. This may be one of the mechanisms by which cholecystokinin can prevent the development of morphine tolerance as reported previously (Watkins et al., 1984; Kellstein and Mayer, 1991).

Thus, either of the two hypotheses (configurational similarity change and endogenous agonists) displays some consistencies 
and inconsistencies with known experimental observations. It is our interest in future studies to investigate these and other possibilities further. It should also be emphasized that the proposed two hypotheses may not be mutually exclusive in terms of their roles in neural and molecular mechanisms of narcotic tolerance and NITH. For instance, configurational changes in EAA receptors may prime EAA receptors, thereby facilitating their activation in response to the released endogenous EAA following chronic morphine administration.

\section{Role of PKC and the associated intracellular mechanisms in NITH}

Despite the unsolved mystery as to how EAA receptors become involved and activated in the neural process of the development of narcotic tolerance and NITH, both previous (Kolesnikov et al., 1993; Mayer et al., 1993) and present results clearly indicate that intracellular second messenger systems (PKC and nitric oxide), consequent to NMDA/non-NMDA receptor activation, play a critical role in neural and molecular mechanisms of narcotic tolerance and NITH. Given the properties of EAA receptors and the associated intracellular second messenger systems (Cotman and Monaghan, 1989; Mayer and Miller, 1990; Wilcox, 1991), we hypothesize that the initial coactivation of NMDA and non-NMDA receptors within the spinal cord, somehow triggered by exogenous opiates, enables $\mathrm{Na}^{+}$and, most importantly, $\mathrm{Ca}^{2+}$ influx through ligand-gated and/or voltage-sensitive ion channels (Cotman and Monaghan, 1989; Mayer and Miller, 1990; Wilcox, 1991). The activation of the non-NMDA receptor helps to remove $\mathrm{Mg}^{2+}$ blockade by partial depolarization of the neuronal membrane (MacDonald and Nowak, 1990; Mayer and Miller, 1990). As shown in Figure 5, the resultant activation of intracellular second messenger systems such as PKC translocation/activation and nitric oxide production as well as the regulation of gene expression may induce a number of subcellular functional changes including modulation of ion channel activity (Kaczmarek, 1987; Numann et al., 1991; West et al., 1991) and enduring changes in synaptic efficacy (Olds et al., 1989; Collingridge and Singer, 1990; Madison et al., 1991; Wang et al., 1992). The modulation of the $\mathrm{K}^{+}$channel complex by PKC (Alkon et al., 1988) may reduce the efficacy of the opiate receptor-K ${ }^{+}$ channel activity (functional downregulation), resulting in the development of tolerance to the analgesic effect of morphine. On the other hand, the modulation by PKC of the NMDA receptor (Chen and Huang, 1992) and the non-NMDA receptor (Wang et al., 1992) may increase the efficacy of the NMDA receptor- $\mathrm{Ca}^{2+}$ channel complex and non-NMDA receptor-Na+ channel complex (functional upregulation), leading to the development of hyperexcitability. The hyperexcitability of spinal cord neurons may, on the one hand, counteract opiate effects thereby exacerbating tolerance and, on the other hand, lead to the development of NITH resulting in hyperalgesic responses to peripheral noxious stimulation in the absence of exogenous opiates.

A growing body of evidence suggests that similar neural and molecular mechanisms are involved in neurogenic and inflammatory hyperalgesia (Davar et al., 1991; Simon et al., 1991; Coderre and Melzack, 1992a,b; Mao et al., 1992b,f, 1993; Ren et al., 1992a,b; Yamamoto and Yaksh, 1992; Tal and Bennett, 1993; Yamamoto et al., 1993). Both NITH and neurogenic and inflammatory hyperalgesia involve CNS neuronal plastic changes resulting from EAA receptor activation and subsequent intracellular changes. The difference may be that in the former type
EXOGENOUS MORPHINE

$\checkmark$

EAA RELEASE FROM INTERNEURONS, DESCENDING PATHWAYS, PRIMARY AFFEREMTS?

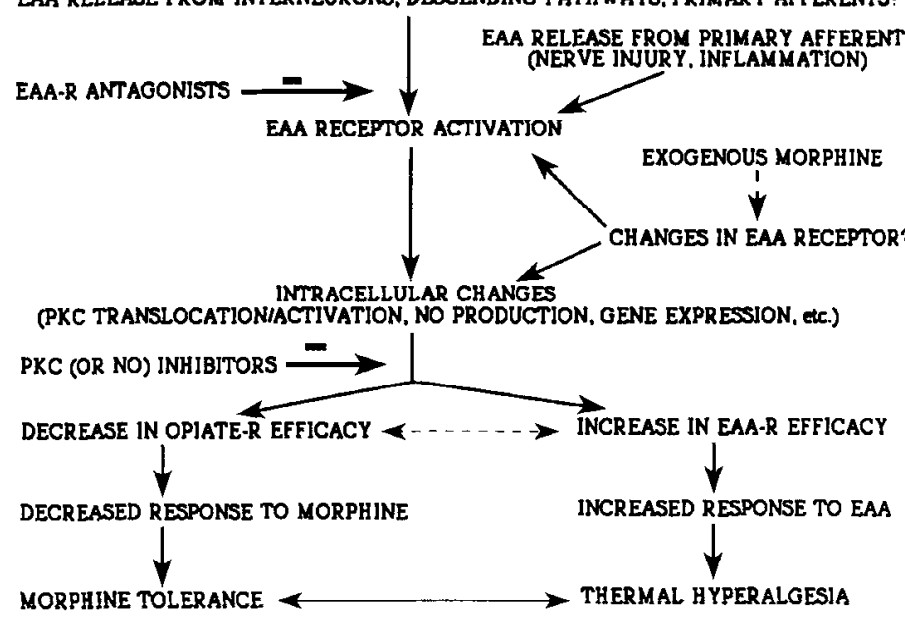

Figure 5. Schematic presentation of possible neural mechanisms subserving the development and expression of NITH and narcotic tolerance. The abnormal coactivation of NMDA and non-NMDA receptors, resulting from EAA release from interneurons, descending pathways, and/or primary afferents as well as possible configurational changes coupled with opiate receptor activation, initiates intracellular second messenger systems such as $\mathrm{PKC}$ translocation/activation, production of nitric oxide $(N O)$, and the regulation of gene expression. In turn, changes in $\mathrm{K}^{+}$channel activity may result in functional downregulation of opiate receptors, leading to the development of morphine tolerance, while changes in $\mathrm{Na}^{+}$and $\mathrm{Ca}^{2}$ ' channel activity may enhance NMDA and non-NMDA receptor aclivity, resulting in the development of NITH. Similar changes may be initiated by the excessive release of EAAs from primary afferents induced by peripheral nerve injury or inflammation. Such EAA receptor-mediated neuronal plastic changes may be interrupted by NMDA and non-NMDA receptor antagonists or intracellular inhibitors of PKC and/or nitric oxide.

such central changes are initiated by central opiate effects and in the latter type such central changes occur as a result of the release of EAAs from primary afferents (Fig. 5).

Several previous and present experimental observations support EAA receptor-mediated intracellular mechanisms subserving NITH. First, GM1 ganglioside, an intracellular inhibitor of PKC translocation/activation (Vaccarino et al., 1987; Costa and Rodbell, 1988; Favaron et al., 1988; Magal et al., 1990), potently prevented the development of both morphine tolerance and NITH. Second, spinal cord levels of membrane-bound PKC (the translocated form) reliably increase in morphine-tolerant rats, a process also potently inhibited by intrathecal GM1 administration (Mayer et al., 1993). Third, since PKC-mediated changes in neuronal excitability that lead to the development of NIT H conceivably have developed gradually over the period of chronic morphine treatment as proposed above, a single treatment with GMl ganglioside (a PKC inhibitor) is unlikely to reverse NITH that has already been established. Indeed, in the present experiments, a single GMl treatment failed to reverse NITH. Fourth, our recent study utilizing a behavioral test (caudally directed biting and scratching) suggests increases in spinal cord NMDA and non-NMDA receptor activity in morphinetolerant rats with demonstrable NITH (J. Mao, D. D. Price, and D J. Mayer, unpublished observations). In this study, biting and scratching elicited by intrathecal NMDA or kainate were increased in morphine-tolerant rats. On the other hand, substance $\mathrm{P}$, a neuropeptide that activates a component efferent to the site 
of NMDA and non-NMDA receptors within the neural circuitry that mediates biting and scratching in rats (Frenk et al., 1988; Mao et al., 1992a), did not produce increased responses in tolerant rats. Finally, since the expression of NITH is thought to be mediated through increased activity of NMDA and nonNMDA receptors, EAA receptor antagonists would be expected to reverse the NITH that has been established. In the present experiments, MK 801 and CNQX, which block NMDA and nonNMDA EAA receptors, respectively, indeed potently reversed NITH. In contrast, although the development of morphine tolerance is related to the activation of NMDA/non-NMDA receptors and subsequent intracellular events as proposed above, the expression of tolerance may be mainly related to the decreased responsiveness of the opiate receptor to morphine. This may explain why a single treatment with the NMDA receptor antagonist fails to reverse morphine tolerance as demonstrated in previous experiments (Trujillo and Akil, 1991). Nevertheless, systematic investigations on the roles of EAA receptors and associated intracellular second messenger systems as well as their relationships are likely to elucidate neural and molecular mechanisms of narcotic tolerance and NITH

\section{Implications for clinical narcotic treatment}

A major drawback of narcotic analgesics for the treatment of pain is the development of tolerance and dependence. The development of tolerance necessitates an increase in drug doses, which results in serious side effects, while the presence of severe physical dependence makes narcotic withdrawal extremely unpleasinn. That hyperalgesia develops in association with the development of morphine tolerance as demonstrated in the present experiments raises the possibility that the decreased efficacy of narcotics following the repeated administration may be the result of the development of both narcotic tolerance and NITH; that is, the development of narcotic tolerance may be exacerbated following the development of NITH. In this sense, a subject treated with narcotics may perceive more pain, in part due to the development of NITH, in response to a preexisting painful condition even though there is actually no substantial increase in the intensity of peripheral factors causing pain. Thus, progressively higher narcotic doses are needed to overcome the loss of analgesic effects of narcotics due to the development of both tolerance and NITH. In turn, a vicious cycle may be initiated involving higher narcotic doses, more tolerance, and greater NITH. This potential interaction between the development of narcotic tolerance and NITH conceivably has contributed to a number of clinical conditions such as postoperative pain and cancer pain in which the use of narcotic analgesics is often the only remaining choice (Wall and Melzack, 1984; Wall, 1988). In other words, the need for higher narcotic doses in the process of treating these painful conditions may be in part due to the development of NITH, which itself results from narcotic administration.

Just as pain can be exacerbated by narcotic tolerance, it is conceivable that narcotic tolerance is exacerbated by pain, since the development of tolerance and NITH have been shown to be mediated by NMDA/non-NMDA receptor activation and intracellular PKC changes. Pathological conditions such as neurogenic and inflammatory pain states in which central NMDA and non-NMDA receptor activation and subsequent PKC translocation/activation are critically involved (Davar et al., 1991; Mao et al., 1992b-d,f, 1993; Yamamoto and Yaksh, 1992; Tal and Bennett, 1993) may facilitate the development of narcotic tolerance. Thus, in the case of neurogenic or inflammatory pain states, the activation of NMDA and non-NMDA receptors involved in the development of both tolerance and NITH may be induced by abnormal release of EAA from the affected primary afferents (Fig. 5). Consequently, the development of narcotic tolerance may be greatly exacerbated upon exposure to exogenous narcotics under such circumstances. This may explain, at least in part, why narcotic analgesics are said to be relatively ineffective in ameliorating neuropathic pain syndromes including hyperalgesia in both clinical and laboratory studies (Davar and Maciewicz, 1989; Portenoy et al., 1990; Dubner, 1991 b; Kupers et al., 1991).

Should such a process be involved in a variety of clinical pain states treated with narcotic analgesics, the use of NMDA and non-NMDA receptor antagonists or intracellular inhibitors blocking one or more of the related second messenger systems in combination with narcotic analgesics may prove useful in preventing the development of narcotic tolerance and the associated hyperalgesia. The clinical utility of narcotic analgesics could thereby be greatly enhanced. In support of this view, the use of MK 801 has been shown to increase the analgesic effect of morphine on thermal hyperalgesia in a rat model of carrageenan-induced inflammation (Yamamoto et al., 1993). It can be anticipated that further clarification of interactions between the development of narcotic tolerance and NITH at the level of neural circuitry as well as at the level of intracellular events will help to better understand hyperalgesia that may be common to central hyperalgesic states associated with morphine tolerance in particular as well as diverse pathological etiologies in general.

\section{References}

Akil H, Mayer DJ (1972) Antagonization of stimulation produced analgesia by p-CPA, a serotonin synthesis inhibitor. Brain Res 44 : 692-697.

Alkon DL, Naito S, Kubota M, Chen C, Bank B, Smallwood J, Gallant P, Rasmussen $\mathrm{H}$ (1988) Regulation of Hermissenda $\mathrm{K}^{+}$channels by cytoplasmic and membrane-associated C-kinase. J Neurochem $5 \mathrm{I}$ : 903-917.

Baker TB, Tiffany ST (1985) Morphine tolerance as habituation. Psychol Rev 92:78-108.

Bederson JB, Fields HL, Barbaro NM (1990) Hyperalgesia during naloxone-precipitated withdrawal from morphine is associated with increased on-cell activity in the rostral ventromedial medulla. Somatosens Mot Res 7:185-203.

Ben Eliyahu S, Marek P, Vaccarino AL, Mogil JS, Sternberg WF, Liebeskind JC (1992) The NMDA receptor antagonist MK-801 prevents long-lasting non-associative morphine tolerance in the rat. Brain Res 575:304-308.

Bennett GJ, Xic YK (1988) A peripheral mononcuropathy in rat that produces disorders of pain sensation like those seen in man. Pain 33: 87-107.

Bonica JJ (1979) Causalgia and other reflex sympathetic dystrophies. In: Advances in pain research and therapy (Bonica JJ, Liebeskind JC, Albe-Fessard DG, eds), pp 141-166. New York: Raven.

Chen L, Huang LYM (1991) Sustained potentiation of NMDA receptor-mediated glutamate responses through activation of protein kinase $C$ by a $\mu$ opioid. Neuron 7:319-326.

Chen L, Huang LYM (1992) Protein kinase C reduces $\mathrm{Mg}^{2+}$ block of NMDA-receptor channels as a mechanism of modulation. Nature $356: 521-523$

Coderre TJ (1992) Contribution of protein kinase $C$ to central sensitization and persistent pain following tissue injury. Neurosci Lett 140:181-184.

Coderre TJ, Melzack R (1991) Central neural mediators of secondary hyperalgesia following heat injury in rats: neuropeptides and excitatory amino acids. Neurosci Lett 131:71-74.

Coderre TJ, Melzack R (1992a) The contribution of excitatory amino 
acids to central sensitization and persistent nociception after formalin-induced tissue injury. J Neurosci 12:3665-3670.

Coderre TJ, Melzack R (1992b) The role of NMDA receptor-operated calcium channels in persistent nociception after formalin-induced tissue injury. J Neurosci 12:3671-3675.

Collingridge GL, Singer W (1990) Excitatory amino acid receptors and synaptic plasticity. Trends Pharmacol Sci 11:290-296.

Costa E, Rodbell M (1988) Receptor-mediated engram: signal transduction and long-term modification of neuronal receptor responses. Psychopharmacol Bull 24:403-407.

Cotman C, Monaghan D (1989) Multiple excitatory amino acid receptor regulation of intracellular $\mathrm{Ca}$ : implications for aging and $\mathrm{Al}$ zheimer's disease. Ann NY Acad Sci 568:138-148.

D'Amour FE, Smith DL (1941) A method for determining loss of pain sensation. J Pharmacol Exp Ther 72:74-79.

Davar G, Maciewicz RJ (1989) Deafferentation pain syndromes. Neurol Clin 7:289-304.

Davar G, Hama A, Deykin A, Vos B, Maciewicz R (1991) MK-801 blocks the development of thermal hyperalgesia in a rat model of experimental painful neuropathy. Brain Res 553:327-330.

Doerr IC, Kristal MB (1991) Amniotic-fluid ingestion enhances morphine analgesia during morphine tolerance and withdrawal in rats. Physiol Behav 50:633-635.

Dubner R (1991a) Neuronal plasticity and pain following peripheral tissue inflammation or nerve injury. In: Proceedings of VIth World Congress on Pain, Vol 5, Pain research and clinical management (Bond M, Charlton E, Woolf CJ, eds), pp 263-276. Amsterdam: Elsevier.

Dubner R (1991b) A call for more science, not rhetoric, regarding opioids and neuropathic pain. Pain 47:1-2.

Dyck PJ, Thomas PK, Lambert EH, Bunge R (1984) Peripheral neuropathy. Philadelphia: Saunders.

Ehrenpreis S, Neidle A (1975) Methods in narcotic research. New York: Dekker.

Favaron M, Manev H, Alho H, Bertolino M, Ferret B, Guidotti A, Costa E (1988) Gangliosides prevent glutamate neurotoxicity in neuronal cultures. Proc Natl Acad Sci USA 85:7351-7355.

Frenk H, Bossut D, Urca GT, Mayer DJ (1988) Is substance P a primary afferent neurotransmitter for nociceptive input? I. Analysis of pain-related behaviors resulting from intrathecal administration of substance $P$ and 6 excitatory compounds. Brain Res 455:223-231.

Gutstein HB, Trujillo KA, Akil H (1992) MK 801 inhibits the development of morphine tolerance in the rat at spinal sites. Soc Neurosci Abstr 18:369.

Hargreaves K, Dubner R, Brown F, Flores C, Joris J (1988) A new and sensitive method for measuring thermal nociception in cutaneous hyperalgesia. Pain 32:77-88.

Hayes RL, Mao J, Price DD, Mayer DJ, Germano A, d'Avella D, Fiori $M$ (1992) Pretreatment with gangliosides reduces nociceptive responses associated with a rodent peripheral mononeuropathy. Pain 48:391-396.

Inoki R, Ohnishi T, Saito K, Maeda S, Matsumoto K, Sakuda M (1990) Chronic morphine administration and in vivo pertussis toxin treatment induce hyperalgesia and enhance ${ }^{3} \mathrm{H}$-nitrendipine binding. Prog Clin Biol Res 328:469-472.

Kaczmarek LK (1987) The role of protein kinase $C$ in the regulation of ion channels and neurotransmitter release. Trends Neurosci 10 30-34.

Kellstein DE, Mayer DJ (1991) Spinal co-administration of cholecystokinin antagonists with morphine prevents the development of opioid tolerance. Pain 47:221-229.

Kest B, Marek P, Liebeskind JC (1992) The specific $N$-methyl-Daspartate (NMDA) receptor antagonist MK 801 blocks U-50,488, but not morphine antinociception. Brain Res 589:139-142.

Kolesnikov YA, Pick CG, Ciszewska GT, Pasternak GW (1993) Blockade of tolerance to morphine but not kappa opioids by a nitric oxide synthase inhibitor. Proc Natl Acad Sci USA 90:5162-5166.

Kupers RC, Konings H, Adriaensen H, Gybels JM (1991) Morphine differentially affects the sensory and affective pain rating in neurogenic pain and idiopathic forms of pain. Pain 47:5-12.

Lester RA, Quarum ML, Parker JD, Weber E, Jahr CE (1989) Interaction of 6-cyano-7-nitroquinoxaline-2,3-dione with the $N$-methylD-aspartate receptor-associated glycine binding site. Mol Pharmacol 35:565-570.

Lodge $\mathrm{D}$, Johnson KM (1990) Noncompetitive excitatory amino acid receptor antagonists. Trends Pharmacol Sci 11:81-86.
MacDonald JF, Nowak LM (1990) Mechanisms of blockade of excitatory amino acid receptor channels. Trends Pharmacol Sci 11:167172 .

Madison DV, Malenka RC, Nicoll RA (1991) Mechanisms underlying long-term potentiation of synaptic transmission. Annu Rev Neurosci 14:379-397.

Magal E, Louis, JC, Aguilera J, Yavin E (1990) Gangliosides prevent ischemia-induced down-regulation of protein kinase $\mathrm{C}$ in fetal rat brain. J Neurochem 55:2126-2131.

Mao J, Coghill RC, Kellstein DK, Frenk H, Mayer DJ (1992a) Calcitonin gene-related peptide enhances substance $\mathrm{P}$-induced behaviors via metabolic inhibition: in vivo evidence for a new mechanism of neuromodulation. Brain Res 574:157-163.

Mao J, Price DD, Mayer DJ, Lu J, Hayes RL (1992b) Intrathecal MK801 and local nerve anesthesia synergistically reduce nociceptive behaviors in rats with experimental peripheral mononeuropathy. Brain Res 576:254-262.

Mao J, Hayes RL, Price DD, Coghill RC, Lu J, Mayer DJ (1992c) Post-injury treatment with GMI ganglioside reduces nociceptive behaviors and spinal cord metabolic activity in rats with experimental peripheral mononeuropathy. Brain Res 584:18-27.

Mao J, Price DD, Hayes RL, Lu J, Mayer DJ (1992d) Intrathecal GMI ganglioside and local nerve anesthesia reduce nociceptive behaviors in rats with experimental peripheral mononeuropathy. Brain Res 584 28-35.

Mao J, Price DD, Mayer DJ, Hayes RL (1992e) Pain-related increases in spinal cord membrane-bound protein kinase $\mathrm{C}$ following peripheral nerve injury. Brain Res 588:144-149.

Mao J, Mayer DJ, Hayes RL, Lu J, Price DD (1992f) Differential roles of NMDA and non-NMDA receptor activation in induction and maintenance of thermal hyperalgesia in rats with painful peripheral mononeuropathy. Brain Res 598:271-278.

Mao J, Price DD, Hayes RL, Lu J, Mayer DJ, Frenk H (1993) Intrathecal treatment with dextrorphan or ketamine potently reduces pain-related behaviors in a rat model of peripheral mononeuropathy. Brain Res 605:164-168.

Marek P, Ben Eliyahu S, Gold M, Liebeskind JC (1991a) Excitatory amino acid antagonists (kynurenic acid and MK-801) attenuate the development of morphine tolerance in the rat. Brain Res 547:77-81.

Marek P, Ben Eliyahu S, Vaccarino AL, Liebeskind JC (1991b) Delayed application of MK-801 attenuates development of morphine tolerance in rats. Brain Res 558:163-165.

Mayer DJ, Mao J, Price DD (1993) The development of morphine tolerance is associated with changes in membrane-bound protein $\mathrm{ki}$ nase $C$ in the rat spinal cord. Soc Neurosci Abstr 19:1796.

Mayer ML, Miller RJ (1990) Excitatory amino acid receptors, second messengers and regulation of intracellular $\mathrm{Ca}^{2}+$ in mammalian neurons. Trends Pharmacol Sci 11:254-260.

Mitchell JJ, Anderson KJ (1991) Quantitative autoradiographic analysis of excitatory amino acid receptors in the cat spinal cord. Neurosci Lett 124:269-272.

Numann R, Catterall WA, Scheuer T (1991) Functional modulation of brain sodium channels by protein kinase $\mathrm{C}$ phosphorylation. Science 254:115-118.

Ohnishi T, Saito K, Macda S, Matsumoto K, Sakuda M, Inoki R (1990) Intracerebroventricular treatment of mice with pertussis toxin induces hyperalgesia and enhances ${ }^{3} \mathrm{H}$-nitrendipine binding to synaptic membranes: similarity with morphine tolerance. Naunyn Schmiedebergs Arch Pharmacol 341:123-127.

Olds JL, Anderson ML, McPhie DL, Ataten LD, Alkon DL (1989) Imaging of memory-specific changes in the distribution of protein kinase $C$ in the hippocampus. Science 245:866-869.

Portenoy RK, Foley KM, Inturrisi CE (1990) The nature of opioid responsiveness and its implications for neuropathic pain: new hypotheses derived from studies of opioid infusion. Pain 43:273-277.

Price DD (1988) Psychological and neural mechanisms of pain. New York: Raven.

Ren K, Hylden JL, Williams GM, Ruda MA, Dubner R (1992a) The effects of a non-competitive NMDA receptor antagonist, MK-801, on behavioral hyperalgesia and dorsal horn neuronal activity in rats with unilateral inflammation. Pain 50:331-344.

Ren K, Williams GM, Hylden JL, Ruda MA, Dubner R (1992b) The intrathecal administration of excitatory amino acid receptor antagonists selectively attenuated carrageenan-induced behavioral hyperalgesia in rats. Eur $\mathbf{J}$ Pharmacol 219:235-243.

Seybold VS (1986) Neurotransmitter receptor sites in the spinal cord. 
In: Spinal afferent processing (Yaksh TL, ed), pp 117-139. New York: Plenum.

Siegel S (1988) State dependent learning and morphine tolerance. Behav Neurosei 102:228-232.

Simon DA, Sorkin LS, Chung JM, Owens C, LaMotte RH, Willis WD (1991) Neurogenic hyperalgesia: central neural correlates in responses of spinothalamic tract neurons. J Neurophysiol 66:228-246.

Tal M, Bennett GJ (1993) Dextrorphan relieves neuropathic heatevoked hypcralgesia in the rat. Neurosci Lett 151:107-110.

Tanganelli S, Antonelli T, Morari M, Bianchi C, Beani L (1991) Glutamate antagonists prevent morphine withdrawal in mice and guinea pigs. Neurosci Lett 122:270-272

Trujillo KA, Akil H (1991) Inhibition of morphine tolcrance and dependence by the NMDA receptor antagonist MK-80 I. Science 251: $85-87$.

Tung AS, Yaksh TL (1982) In vivo evidence for multiple opiate receptors mediating analgesia in the rat spinal cord. Brain Res 247:7583.

Vaccarino F, Guidotti A, Costa E (1987) Ganglioside inhibition of glutamate-mediated protein kinase C translocation in primary cultures of cerebellar neurons. Proc Natl Acad Sci USA 34:8707.

Wall PD (1988) The prevention of postoperative pain. Pain 33:289 290.

Wall PD, Melzack R (1984) Textbook of pain. New York: Churchill Livingstone.

Wang LY, Dudek EM, Browning M, MacDonald JF (1992) Protein kinase $C$ modulates glutamate receptors (kainate/AMPA) and synaptic transmission in cultured hippocampal neurons. Soc Neurosci Abstr 18:653.
Watkins JR, Kinscheck IB, Mayer DJ (1984) Potentiation of opiate analgesia and apparent reversal of morphine tolerance by proglumide. Science 224:395-396.

West JW, Numann R, Murphy BJ, Scheuer T, Catterall WA (1991) A phosphorylation site in the $\mathrm{Na}^{+}$channel required for modulation by protein kinase C. Science 254:866-868

Westbrook RF. Greeley JD (1992) Conditioned tolerance to morphine hypoalgesia: compensatory hyperalgesia in the experimental group or conditioned hypoalgesia in the control group? Q J Exp Psychol [B] 45:161-187.

Wilcox G (1991) Excitatory neurotransmitters and pain. In: Proceedings of the VIth World Congress on Pain (Bond MR, Charlton JE, Woolf CJ, eds), pp 97-114. New York: Elsevier.

Willis WD (1985) The pain system. New York: Karger.

Yaksh TL, Harty GJ (1988) Pharmacology of the allodynia in rats evoked by high dose intrathecal morphine. J Pharmacol Exp Ther 244:501-507.

Yaksh TL, Harty GJ, Onofrio BM (1986) High dose of spinal morphine produce a nonopiate receptor-mediated hyperesthesia: clinical and theoretic implications. Anesthesiology 64:590-597.

Yamamoto T, Yaksh TL (1992) Spinal pharmacology of thermal hyperalgesia induced by constriction injury of sciatic nerve. Excitatory amino acid antagonists. Pain 49:121-128.

Yamamoto T, Shimoyama N, Mizuguchi T (1993) The effect of morphine, MK 801, an NMDA antagonist, and CP-96,345, an NK1 antagonist, on the hyperesthesia evoked by carrageenan injection in the rat paw. Anesthesiology 78:124-133. 